\title{
Controversies in the management of childhood meningitis
}

Bacterial meningitis-long known as cerebrospinal fever-continues to challenge clinicians. Serum therapy decreased the case fatality to $40-50 \%$ in the early 20th century; sulphonamides, penicillin and chloramphenicol reduced mortality further to $5-10 \%$, but thereafter no significant decline has taken place, despite the appearance of various new antimicrobial agents. Excluding meningococcal epidemics that repeatedly hit subSaharan Africa and, occasionally, other regions, meningitis caused c. 614000 cases worldwide in 1990 , with 180000 deaths and 75000 severe hearing impairments [1]. These are likely to be gross estimates.

Since efforts to improve the prognosis with newer and newer antimicrobials have become becalmed, attention has turned to other therapeutic approaches. Three important issues have emerged: how to cope with rising bacterial resistance; the place of dexamethasone; and the role of fluid restriction in treatment. These questions have more than one answer.

Beyond the neonatal period, the three major pathogens worldwide are Haemophilus influenzae type b (Hib), pneumococci and meningococci. All used to be susceptible to the classic combination of chloramphenicol plus penicillin or ampicillin, to one of those alone, or to an expanded-spectrum cephalosporin such as cefotaxime or ceftriaxone [2]. However, pneumococcal resistance to penicillin and, to a lesser extent, to chloramphenicol has emerged and complicates the choice of primary therapy. $\beta$-Lactamase producing Hib strains pose another problem. A switch to cefotaxime, ceftriaxone, cefepime, meropenem or, perhaps, one of the newer quinolones is an option if the high cost can be afforded, but even ampicillin is too expensive in some African and other countries.

Fortunately, inexpensive chloramphenicol plus penicillin (or ampicillin) can still be used successfully in many parts of the world. Chloramphenicol has the additional advantage that at least a part of the treatment can be accomplished orally-a great advantage in certain conditions. Sulphonamides and cotrimoxazole should also not be forgotten if susceptibility allows. Whether vancomycin or rifampicin should be added to cefotaxime or ceftriaxone in case of resistant pneumococci as has been suggested [3], awaits validation by further clinical evidence.
It is now clear that treatment regimens in meningitis (as in many other infections) are often unnecessarily long. Good data show that meningococcal meningitis is treatable with one single dose (!) of long-acting penicillin [4] or chloramphenicol [5], and pneumococcal and Hib diseases with a 7-day course of ampicillin or third-generation cephalosporins [2]; the only known exception is treatment of pneumococcal meningitis with chloramphenicol, in which slightly longer medication is sometimes needed [2]. Still, many physicians throughout the world prescribe antimicrobial therapy for 10-14 days. If the grounds for this are that some recrudescences of neonatal meningitis have been described with shorter courses, then they are mistaken.

In Nepal [6], an alternative, if risky approach, has been successful: the dose of ceftriaxone was reduced to 50 (instead of the normal $80-100$ ) $\mathrm{mg} / \mathrm{kg}$ daily. The rationale was that the reduced dose, given intramuscularly for a week, cost less in total than the conventional 14-day course of chloramphenicol plus penicillin intravenously. It is difficult to challenge the logic of this solution.

Dexamethasone as adjunctive therapy in meningitis has gained much attention during the past decade. No doubt it relieves the inflammatory response, and this can be documented by various changes in the cerebrospinal fluid or blood [7]; but whether this has any real impact is questionable. There are slightly fewer sequelae among dexamethasone recipients, especially after Hib meningitis, provided that dexamethasone is instituted concomitantly with or, preferably, before the first dose of antimicrobial drug. Fatality rates are not altered.

The problem is that, in most of the world, use of antimicrobial drugs is uncontrolled and bacterial meningitis often has to be treated without identification of the causative agent. Unsurprisingly, a prospective trial in Pakistan, in which dexamethasone was given before parenteral antimicrobial therapy [8], failed to show benefit of the drug; both mortality and complications were (non-significantly) higher among dexamethasone recipients.

It may be argued that the negative results in this particular study were due to the possible use of oral antimicrobial agents, or that Islamabad is not char- 
acteristic of many other cities. A statistical difference in favour of dexamethasone can be recognised by combining other studies. But in real life you cannot separate a subgroup or optimal setting-children who have not received pretreatment antimicrobial therapy, who develop meningitis by a specific agent, who are promptly referred to a Western hospital, and then receive dexamethasone $15 \mathrm{~min}$ before treatment-and then make recommendations as though this were representative of meningitis in general.

Should dexamethasone, then, be given or not? Twenty experts from all over the world, convened under the auspices of WHO, recently came to the conclusion that the present data are not strong enough to warrant routine dexamethasone treatment, except for proven or likely Hib meningitis. Hence, there is not much place for this approach in countries with active Hib vaccination programmes and declining incidence of this infection. This is supported by a recent metaanalysis [9]. Potential adverse effects of dexamethasone are minor, and per se do not contra-indicate the drug. If dexamethasone is used (usually $0.6 \mathrm{mg} / \mathrm{kg}$ daily in four doses), a 2-day course suffices [10].

As to fluid restriction, we have, again, a lot to learn from the Indian subcontinent. A prospective study (in which patients were probably not primarily dehydrated) [11] indicated that fluid restriction was harmful: children with extracellular water reduction of $\geqslant 10 \mathrm{ml} / \mathrm{kg}$ within $48 \mathrm{~h}$ had a significantly lower intact survival $(36 \%)$ than those in whom there was less or no reduction $(64 \%, p<0.05)$. Rather than being inappropriate, increased anti-diuretic hormone (ADH) secretion seems an appropriate response by the body fighting against decreased cerebral blood flow and impaired cerebral perfusion pressure. This study strongly refutes the widely held view. that most patients should be treated by reducing the water intake, since death from meningitis is often caused by increased intracranial pressure, which is worsened by fluid overload, hyponatraemia, and hypernatriuria, sometimes leading to 'inappropriate' secretion of $\mathrm{ADH}$ [12]. On the contrary, most patients are, in fact, hypovolaemic owing to extravascularisation of water (which cannot be detected by weighing the patient), and these patients need replacement of any deficit plus full maintenance fluids. No-one has demonstrated that the syndrome of inappropriate secretion of $\mathrm{ADH}$, if it is to develop, is preventable by fluid restriction, but a third of children with bacterial meningitis suffer from significantly reduced cerebral blood flow [13]. To lower autoregulatorily increased mean arterial pressure by exacerbating hidden hypovolaemia with fluid restriction is probably very dangerous.

No doubt fluid restriction does normalise body water, as well as serum sodium and osmolality, but this also occurs in children on normal fluid maintenance [11]. Similarly, in rabbits given a liberal fluid regimen, cerebral blood flow decreased and cerebrospinal fluid lactate increased (suggesting cerebral ischaemia) only if fluids were restricted to $50 \mathrm{ml} / \mathrm{kg}$ daily [14]. Interestingly, children treated with a rather free fluid policy lower their plasma ADH concentration sooner than those with fluid restriction [15].

Obviously, fluid restriction should not be entertained routinely [11] because restriction affects cerebral oedema minimally (if at all) and, if pursued to excess, may induce hypotension, cerebral hypoxia and further increased intracranial pressure. Instead of colloids, isotonic crystalloids are justified on a scientific basis [16].

H. PELTOLA HUCH, Hospital for Children and Adolescents,

11 Stenbäck St FIN-00290 Helsinki, Finland

\section{References}

1. Murray CJ, Lopez AD. Global burden of disease and injury series: global health statistics. Cambridge, Harvard University Press. 1996.

2. Peltola H, Anttila M, Renkonen O-V, the Finnish Study Group Randomised comparison of chloramphenicol, ampicillin, cefotaxime, and ceftriaxone for childhood bacterial meningitis. Lancet 1989; 1: 1281-1287.

3. John JJ. Treatment failure with use of a third-generation cephalosporin for penicillin-resistant pneumococcal meningitis: case report and review. Clin Infect Dis 1994; 18: 188-193.

4. MacFarlane JT, Anjorin FI, Cleland PG et al. Single injection treatment of meningococcal meningitis. 1. Long-acting penicillin. Trans $R$ Soc Trop Med Hyg 1979; 73: 693-697.

5. Rey M, Ouedraogo L, Saliou P, Perino L. Traitement minute de la méningite cérébrospinale épidémique par injection intramusculaire unique de chloramphenicol (suspension huileuse). Med Mal Infect 1976; 6: 120-124.

6. Sharma PR, Adhikari RK, Joshi MP et al. Intravenous chloramphenicol plus penicillin versus intramuscular ceftriaxone for the treatment of pyogenic meningitis in Nepalese children. Trop Doct 1996; 26: 84-85.

7. Odio CM, Faingezicht I, Paris $M$ et al. The beneficial effects of early dexamethasone administration in infants and children with bacterial meningitis. $N$ Engl $J$ Med 1991; 324: 15251531.

8. Qazi SA, Khan MA, Mughal $\mathrm{N}$ et al. Dexamethasone and bacterial meningitis in Pakistan. Arch Dis Child 1996; 75: 482-488.

9. Prasad K, Haines T. Dexamethasone treatment for acute bacterial meningitis: how strong is the evidence for routine use? J Neurol Neurosurg Psychiatry 1995; 59: 31-37.

10. Syrogiannopoulos GA, Lourida AN, Theodoridou MC et al. Dexamethasone therapy for bacterial meningitis in children: 2versus 4-day regimen. $J$ Infect Dis 1994; 169: 853-858.

11. Singhi SC, Singhi PD, Srinivas B et al. Fluid restriction does not improve the outcome of acute meningitis. Pediatr Infect Dis $J$ 1995; 14: 495-503.

12. Shann F, Germer S. Hyponatraemia associated with pneumonia or bacterial meningitis. Arch Dis Child 1985; 60: 963-966.

13. Ashwal S, Stringer W, Tornasi L, Schneider S, Thompson J, Perkin R. Cerebral. blood flow and carbon dioxide reactivity in children with bacterial meningitis. $J$ Pediatr 1990; 117: 523-530.

14. Tureen JM, Täuber MG, Sande MA. Effect of hydration status on cerebral blood flow and cerebrospinal fluid lactic acidosis in rabbits with experimental meningitis. $J$ Clin Invest 1992; 89: 947-953

15. Powell KR, Sugarman LI, Eskenazi AE et al. Normalization of plasma arginine vasopressin concentrations when children with meningitis are given maintenance plus replacement fluid therapy. J Pediatr 1990; 117: 515-522.

16. Zornow MH, Prough DS. Fluid management in patients with traumatic brain injury. New Horizons 1995; 3; 488-498. 